\title{
Micropropagation of Eucalyptus viminalis Labill
}

\author{
M. Wiecheteck ${ }^{1}$, M.E. Cortezzi Graça ${ }^{2}$ and A.J. de Araújo ${ }^{3}$ \\ 1 UFPR, Pisa Florestal S.A., Rod. PR-151, km 232, 84200, Jaguariaíva/PR, \\ 2 CNPF, Centro Nacional de Pesquisa de Florestas/Embrapa, C.P. 3319, 80001, Curitiba/PR, and \\ 3 UFPR, School of Forestry, C.P. 2959, 80001, Curitiba/PR, Brazil
}

\section{Introduction}

Eucalyptus viminalis has been established in southern Brazil mainly because of its frost tolerance and growth potential. However, its slow growth rate and undesirable stem form, due mainly to a narrow genetic base, have limited its extensive use. Vegetative propagation of selected genotypes of this species has not been very encouraging, the major constraint being a low percentage of rooted cuttings (Cunningham and Mott, 1985). Considerable effort has been exerted to develop in vitro techniques for rapid clonal propagation and for improvement of Eucalyptus. Recent studies have shown that multiple axillary buds were obtained by using in vitro techniques of juvenile $E$. viminalis (Mehra Palta, 1982; Cunningham and Mott, 1985). However, plant regeneration was low due to poor rhizogenesis (Mehra Palta, 1982). This paper describes a more successful system for micropropagation of E. viminalis.

\section{Materials and Methods}

Nodal segments (about $1 \mathrm{~cm}$ long) from greenhouse-grown $E$. viminalis seedlings were washed under running water for $1 \mathrm{~h}$, soaked in a $10 \%(\mathrm{v} / \mathrm{v})$ commercial detergent for $20 \mathrm{~min}$, and afterwards in a $100 \mathrm{ml}$ solution of $1 \%$ $\mathrm{NaClO}$ with 2 drops of Tween 20 for $10 \mathrm{~min}$. The disinfectants were removed by 3 successive rinses in autoclaved, distilled water. Explants were grown on half-strength MS medium (Murashige and Skoog, 1962) supplemented with NAA and BAP, both at 0.1 mg. $\left.\right|^{-1}, 2 \%$ sucrose, $0.8 \%$ Difco Bacto agar and vitamins as described by Gamborg and Wetter (1975). At the multiplication phase, different levels of NAA $\left(0,0.1,0.5,1.0\right.$ or $\left.1.5 \mathrm{mg} \cdot \mathrm{l}^{-1}\right)$ and $\operatorname{BAP}\left(0,0.05,0.1,0.2,0.5\right.$ or $\left.\left.1.0 \mathrm{mg} \cdot\right|^{-1}\right)$ were added to the MS medium. In the shoot elongation experiment, IBA (0 or $1.0 \mathrm{mg} \cdot \mathrm{l}^{-1}$ ) and $\mathrm{GA}_{3}\left(0,0.1\right.$ or $\left.1.0 \mathrm{mg} \cdot \mathrm{I}^{-1}\right)$ with or without activated charcoal (A.C.) $\left(15 \mathrm{mg}^{-1}\right)$ were used in MS medium. Elongated shoots were subculfured onto an MS or half-strength MS medium with different levels of IBA $(0.1,0.5$ or 1.0 $\mathrm{mg} \mathrm{I}^{-1}$ ) and $\mathrm{KIN}$ ( 0 or $0.1 \mathrm{mg}^{-1}$ ) to initiate roots. The $\mathrm{pH}$ of the medium was adjusted to 5.8. The experiments were carried out in a randomized complete block design, each treatment being repeated 15- 30 times depending upon the phase. Cultures were maintained

Abbreviations: NAA: naphthalene acetic acid; BAP: benzylaminopurine; IBA: indole butyric acid: GA 3 : gibberelic acid 3; KIN: kinetin. 
under a $16 / 8 \mathrm{~h}$ light/dark photoperiod and temperature of $25 \pm 2 \circ$. After the rooting phase, plantlets were transferred to a shadehouse.

\section{Results}

Optimal shoot proliferation was achieved by adding $0.2 \mathrm{mg}^{-1}$ of BAP and 0.1 $\mathrm{mg}^{-1}$ of NAA (4.6 shoots/explant) (Fig. 1). As the concentration of BAP increased, shoot formation decreased. Although the multiplication rate was higher with 0.5 or $1.0 \mathrm{mg}^{-1}$ of NAA, the lowest concentration of NAA $\left(0.1 \mathrm{mg}^{-1}\right)$ provided more vigorous shoots than the other treatments.

The fact that lower levels of BAP gave higher multiplication rates suggested that levels below $0.2 \mathrm{mg}^{-1}$ could increase shoot proliferation. This was confirmed with $0.1 \mathrm{mg} \cdot 1-1$, which gave the highest multiplication rate (6.2 shoots/explant). A decreasing trend of the rate of multiplication was observed when levels of BAP were reduced below $0.1 \mathrm{mg}^{-1}+$ (Fig. 2).

During the elongation phase, the use of $15 \mathrm{~g}^{-1}$ of A.C. with or without $0.1 \mathrm{mg} \cdot \mathrm{I}^{-1}$ of IBA in MS medium resulted in the most elongated shoots (Fig. 3). Shoots grown on medium containing A.C. only showed the true morphological characteristics of the species. The use of $\mathrm{GA}_{3}$ was found to be detrimental to elongation of $E$. viminalis shoots.

The elongated shoots produced more roots on half-strength MS medium with 0.5 or $1.0 \mathrm{mg} \cdot \mathrm{I}^{-1}$ of IBA, although better root morphology was observed with $0.5 \mathrm{mg}^{-1}$ of IBA (Table I).

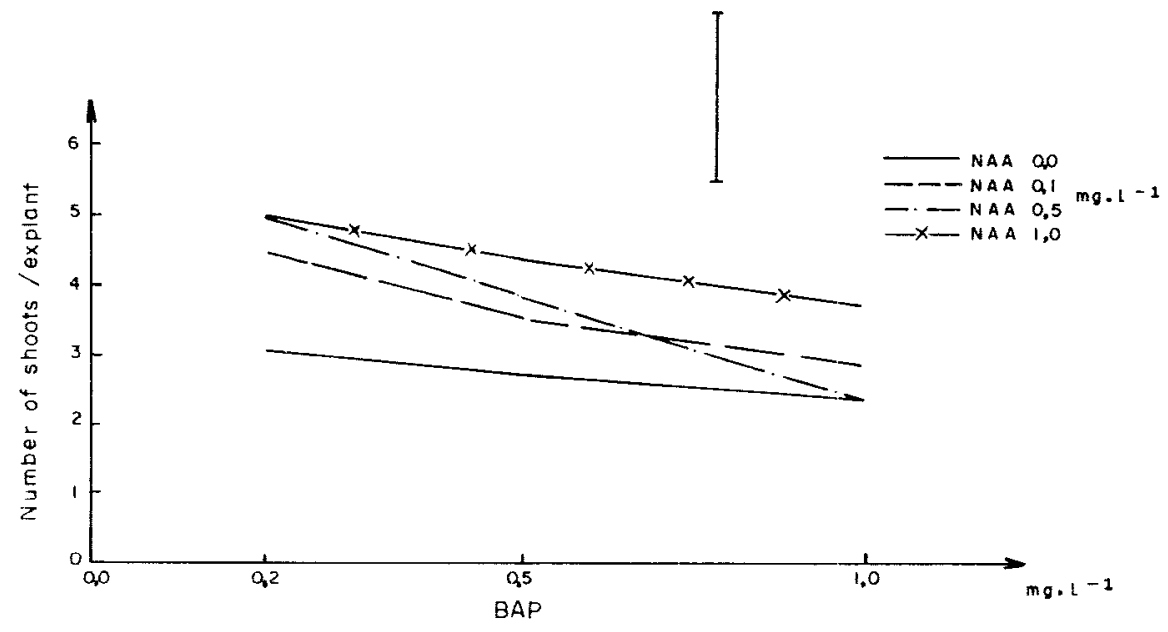

Fig. 1. The influence of levels of BAP and NAA on shoot multiplication of $E$. viminalis. Vertical bar indicates the maximum SE. 


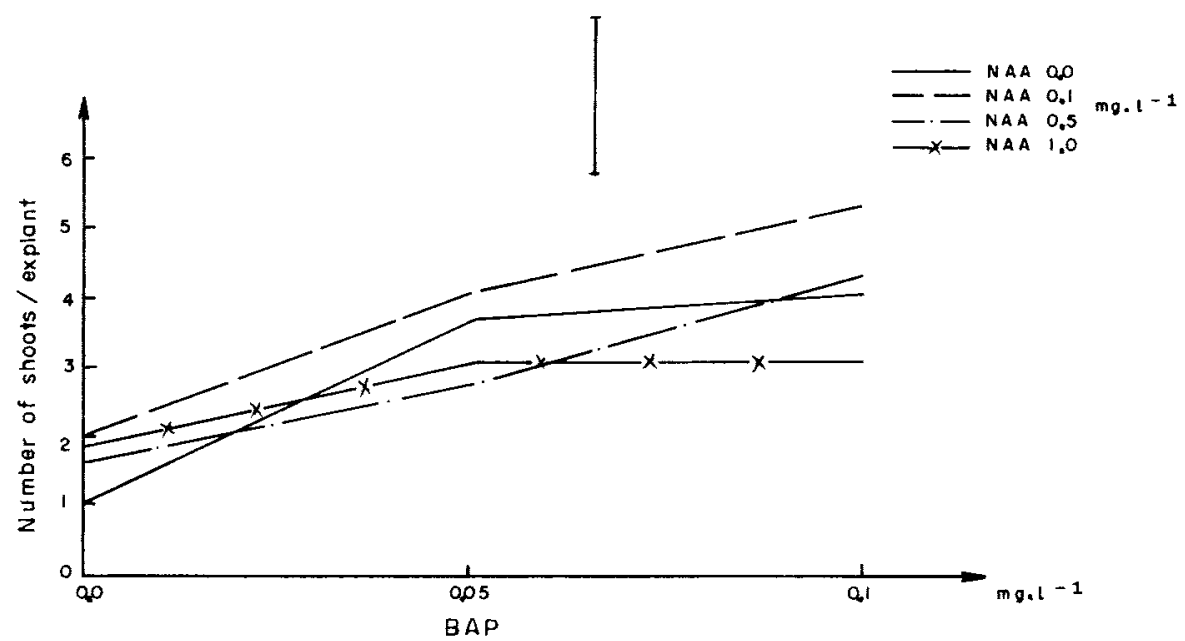

Fig. 2. Shoot mutiplication of $E$. viminalis as a function of BAP and NAA levels. Vertical bar indicates the maximum SE.

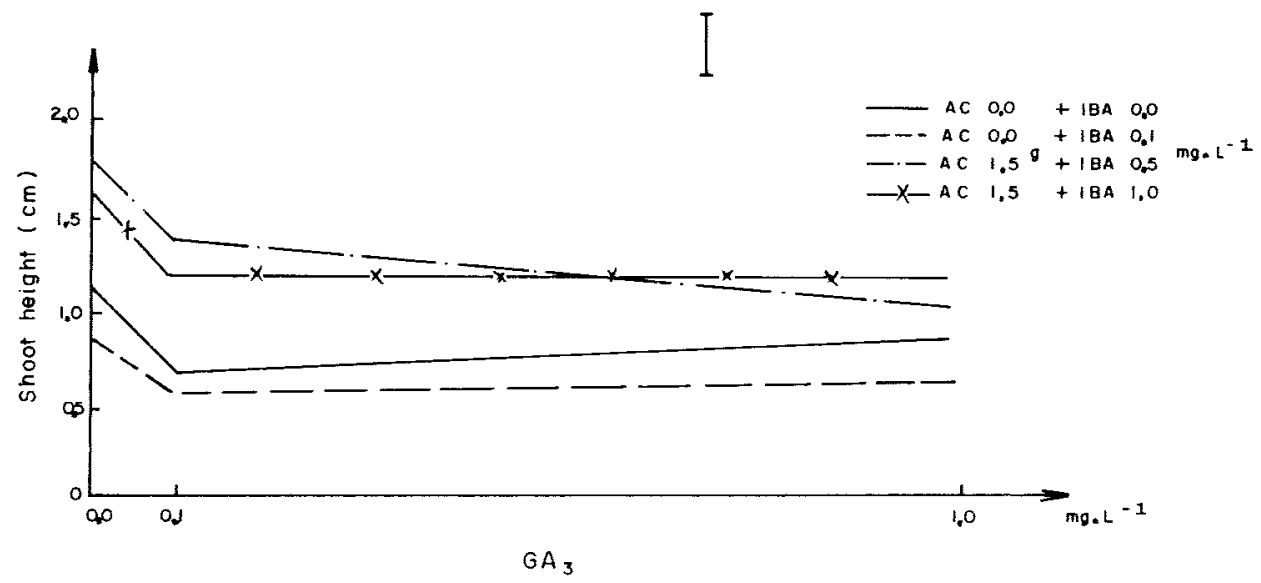

Fig. 3. The influence of $\mathrm{GA}_{3}$ on the shoot height of $E$. viminalis. Vertical bar indicates the maximum SE.

Table I. Root formation on E. viminalis shoots as a function of MS media and IBA and KIN levels, expressed as rooting percentage of total rooted shoots.

\begin{tabular}{llllll}
\hline IBA $\left(m g \cdot^{-1}\right) a$ & \multicolumn{2}{l}{$K I N\left(m g \cdot^{-1}\right)$ in $M S$} & & \multicolumn{2}{l}{$K I N\left(m g \cdot{ }^{-1}\right)$ in $M S / 2$} \\
\cline { 2 - 3 } \cline { 5 - 6 } & 0.0 & 0.1 & & 0.0 & 0.1 \\
\hline 0.1 & $5.5 \pm 5.4$ & $22.2 \pm 9.8$ & & $22.2 \pm 9.8$ & $22.2 \pm 9.8$ \\
0.5 & 0 & $11.1 \pm 7.4$ & & $66.6 \pm 11.1$ & $38.8 \pm 11.5$ \\
1.0 & $16.7 \pm 8.7$ & $16.7 \pm 8.7$ & & $33.3 \pm 11.1$ & $50.0 \pm 11.8$ \\
\hline
\end{tabular}

a Mean of 18 replicates $\pm S D$. 


\section{Discussion and Conclusion}

A more successful system for the micropropagation of $E$. viminalis was developed in this study.

Multiplication rates of 5-6 shoots/explant were obtained by using $0.2 \mathrm{mg}^{-1}$ of BAP and $0.1 \mathrm{mg}^{-1}$ of NAA on MS medium. Although these are higher than those reported to date for $E$. viminalis, they are lower in comparison to other Eucalyptus species. Shoot elongation of E. viminalis was not improved by using $\mathrm{GA}_{3}$. Results were opposite to those expected, since the elongation effect should be one of the main features of $\mathrm{GA}_{3}$. The best root formation $(66.6 \%$ of rooting) was obtained on a half-strength MS medium, supplemented with 0.5 $\mathrm{mg} \cdot \mathrm{I}^{-1}$ of IBA. This study establishes a micropropagation method for juvenile $E$. viminalis which can serve as a basis for the in vitro propagation of adult trees for future improvement programs.

\section{Acknowledgments}

The authors are grateful to Prof. Dr. Mario Takao Inoue and Prof. Dr. Flávio Zanette for their assistance and Mr. Adhemar Villela Filho, Forest Director of Pisa Florestal S.A., for encouragement and support throughout this study.

\section{References}

Cunningham M.W. \& Mott R.L. (1985) Micropropagation of Eucalyptus viminalis. Proceedings of the 18th Southern Forest Tree Improvement Conference. Long Beach, Mississippi. pp. 54-63

Gamborg O.L. \& Wetter L.R. (1975) In: Plant Tissue Culture Methods. National Research Council of Canada, Saskatoon, pp. 109, p. 91.1 Mehra Palta A. (1982) Clonal propagation of Eucalyptus by tisisue culture. Plant Sci. Lett. 26, 1-11

Murashige T. \& Skoog F. (1962) A revised medium for rapid growth and bioassays with tobacco tissue cultures. Physiol. Plant. 15, 473497 